\title{
Differential effects of a nitric oxide donor on reperfusion-induced microvascular dysfunction in diabetic and non-diabetic rats
}

\author{
A. Salas ${ }^{1}$, J. Panés ${ }^{1}$, C. L. Rosenbloom ${ }^{2}$, J. I. Elizalde ${ }^{1}$, D. C. Anderson ${ }^{2}$, D. N. Granger ${ }^{3}$, J.M. Piqué \\ ${ }^{1}$ Department of Gastroenterology, Digestive Diseases Institute, Institute of Biomedical Research August Pi i Sunyer (IDIBAPS), \\ Hospital Clinic, Barcelona, Spain \\ ${ }^{2}$ Discovery Research. Pharmacia \& Upjohn Laboratories, Kalamazoo, Michigan, USA \\ ${ }^{3}$ Department of Molecular and Cellular Physiology, Louisiana State University Medical Center, Shreveport, Louisiana, USA
}

\begin{abstract}
Aims/hypothesis. Diabetes is associated with a high incidence of ischaemic disease and impaired nitric oxide responses. Therefore, the aim of the present study was to assess the effect of nitric oxide on ischaemia/ reperfusion (I/R)-induced microvascular responses in an experimental model of diabetes.

Methods. Leucocyte-endothelial cell interactions were studied in mesenteric venules after superior mesenteric artery occlusion $(10 \mathrm{~min})$, at 10 and $30 \mathrm{~min}$ of reperfusion in control and streptozotocininduced diabetic rats. An oxidant-sensitive fluorochrome was used to measure oxidant production during reperfusion. P-selectin and ICAM-1 expression were quantified at 10 and $30 \mathrm{~min}$ of reperfusion respectively, using radiolabelled monoclonal antibodies. The transcription of ICAM-1 mRNA was determined by northern blot. The effect of spermine NONOate, given locally, on all variables studied, was assessed in additional experiments.

Results. Ischaemia/reperfusion induced an enhanced leucocyte accumulation and oxidant production in di-
\end{abstract}

abetic animals. Moreover, I/R enhanced endothelial P-selectin expression in both groups of animals, whereas it only up regulated ICAM-1 endothelial expression and mRNA expression in diabetic rats. Spermine NONOate abrogated to a similar extent leucocyte adhesion and emigration in control and diabetic animals, although the mechanisms underlying this protective effect appear to be different. In control rats Spermine NONOate effectively prevented P-selectin up regulation, whereas in diabetic rats $\mathrm{NO}$ appreciably attenuated the rapid up regulation of ICAM-1 by preventing its transcription.

Conclusions/interpretation. Expression of ICAM-1 is rapidly increased in diabetic, but not control, animals exposed to I/R. The increased endothelial cell adhesion molecule expression, leucocyte-endothelial cell adhesion and oxidant stress induced by $\mathrm{I} / \mathrm{R}$ in diabetic rats are significantly attenuated by exogenous NO. [Diabetologia (1999) 42: 1350-1358]

Keywords ICAM-1, P-selectin, free radicals, inflammation, leucocyte, endothelium.
Received: 31 March 1999 and in revised form: 31 May 1999

Corresponding author: J. Panés, MD, Dept. Gastroenterology, Hospital Clinic, Villarroel 170, 08036 Barcelona, Spain Abbreviations: NO, Nitric oxide; I/R, ischaemia/reperfusion; ICAM-1, intercellular adhesion molecule-1; SP-NO, spermine NONOate [N-(2-Aminoethyl)- $N$-(2-hydroxy-nitrosohydrazino)-1,2-ethylenediamine]; SMA, superior mesenteric artery; $\mathrm{mAb}$, monoclonal antibody; ACE, angiotensin converting enzyme; DHR, dihydrorodhamine; $\mathrm{D}_{\mathrm{v}}$, venular diameter.
Vascular disease accounts for the majority of the clinical complications of diabetes mellitus [1]. The changed vascular reactivity associated with diabetic vascular complications are possibly due to an imbalanced production of relaxing and contracting factors by the endothelium. Evidence showing decreased acetylcholine-induced production of cyclic GMP in aortic rings of diabetic rats [2] and reduced nitric oxide (NO) synthase activity in platelets of diabetic patients [3] suggest an impaired NO bioactivity or production in the diabetic state. This reduced bioavailability of NO could render the vascular endothelium more prone 
to the deleterious effects of ischaemia/reperfusion (I/ R) [4].

Under physiological conditions $\mathrm{NO}$ is known to have a relevant role in tissue preservation not only by regulating vascular tone but also by influencing leucocyte-endothelial interactions [5]. Moreover, during reperfusion, diminution of endothelial-derived NO concentrations, either by a decrease in NO production [6] or as a result of NO inactivation by superoxide anions [7], is a major early event that leads to enhanced neutrophil adherence to endothelial cells and migration across the vascular wall, which eventually results in tissue dysfunction [8]. It has been shown that treatment with exogenous $\mathrm{NO}$ at the onset of reperfusion results in prevention of the increase in mucosal permeability of the gut [9] and in statistically significant attenuation of leucocyte-endothelial cell interactions and leucocyte-platelet aggregation within mesenteric microvessels in the nondiabetic condition [10].

Various mechanisms could account for the protective effects of $\mathrm{NO}$ against I/R injury, including reduction of leucocyte adhesion to postcapillary venules at reperfusion, which possibly results from prevention of adhesion molecule up regulation or from superoxide scavenging or both. Both excessive oxidant production [11] and enhanced adhesion molecule expression [12] have been implicated in the pathobiology of diabetes mellitus. Thus, therapy directed towards restoring NO concentrations could prove to be particularly beneficial in protecting the diabetic vascular endothelium from I/R-induced tissue damage. Accordingly, the main objectives of this study were: firstly to assess the effects of NO given locally on the microvascular and inflammatory response elicited by $\mathrm{I} / \mathrm{R}$ in diabetic animals and compare this effect with the responses observed in non-diabetic controls; and secondly to determine whether the protective effects of NO in this model are related to modulation of oxidant stress or endothelial adhesion molecule expression or both.

\section{Materials and methods}

Animal model of diabetes. Male Sprague-Dawley rats (170-200 g) were rendered diabetic by i.p. injection of $75 \mathrm{mg} / \mathrm{kg}$ streptozotocin (Upjohn; Kalamazoo, Mich., USA). Control rats received saline alone. Hyperglycaemia (glucose concentration $>200 \mathrm{~g} / \mathrm{l}$ ) was confirmed by measurement of glucose concentration in blood samples obtained from the tail vein 2 days after injection. Rats were studied 4 weeks after treatment. This experimental model of diabetes has previously been shown to be associated with considerable microvascular dysfunction [13]. Principles of laboratory animal care (NIH publication No. 86-23, revised 1985) as well as the guidelines of procedures for animal experiments from the Government of Catalonia, were followed.

Assessment of $P$-selectin and intercellular adhesion molecule-1 (ICAM-1) in vivo expression
Animal procedures. At the time of the study, rats were anesthaetized by i.p. injection of thiobutabarbital (Inactin; RBI; Natick, Mass., USA) $(100 \mathrm{mg} / \mathrm{kg}$ body wt in non-diabetic rats and $80 \mathrm{mg} / \mathrm{kg}$ in diabetic rats). The right carotid artery and right jugular vein were cannulated. In sham operated rats and those undergoing $\mathrm{I} / \mathrm{R}$ a silicone tubing was placed around the superior mesenteric artery (SMA). Ischaemia was induced by pulling the tubing for $10 \mathrm{~min}$.

Monoclonal antibodies $(m A b)$. The mAbs used for the in vivo assessment of P-selectin and ICAM-1 expression were: RMP1 , a murine immunoglobulin $\mathrm{G}_{2 \mathrm{a}}\left(\mathrm{IgG}_{2 \mathrm{a}}\right)$ against rat and mouse P-selectin; 1A29, a murine $\mathrm{IgG}_{1}$ against rat ICAM-1 and P-23, a non-binding murine $\mathrm{IgG}_{1}$ directed against human $\mathrm{P}$-selectin. To assess endothelial surface area $9 \mathrm{~B} 9$, a murine $\mathrm{IgG}_{1}$ directed against human angiotensin converting enzyme (ACE), that cross-reacts with rat and monkey ACE, was used. Monoclonal antibodies RMP-1, 1A29 and P-23 were scaled-up and purified by protein A/G chromatography at Pharmacia \& Upjohn Laboratories (Kalamazoo, Mich., USA). The 9B9 was purchased from Chemicon International (Temecula, Calif., USA).

Radioiodination of monoclonal antibodies. Binding mAbs directed against P-selectin (RMP-1), ICAM-1 (1A29) or ACE (9B9) were labelled with ${ }^{125} \mathrm{I}$ and the non-binding $\mathrm{mAb}$ (P-23) was labelled with ${ }^{131} \mathrm{I}$. Radioiodination of the mAbs was done by the iodogen method [14].

To measure endothelial P-selectin expression, a mixture of $5 \mu \mathrm{g}$ of ${ }^{125} \mathrm{I}$-anti-P-selectin mAb (RMP-1), $10 \mu \mathrm{g}$ of unlabelled anti-P-selectin $\mathrm{mAb}$ and $5 \mu \mathrm{g}$ of ${ }^{131} \mathrm{I}$-non-binding $\mathrm{mAb}(\mathrm{P}-23)$ was given through the jugular vein catheter; whereas for ICAM-1 expression assessment, $5 \mu \mathrm{g}$ of ${ }^{125}$ I-anti-ICAM$1 \mathrm{mAb}$ (1A29), $245 \mu \mathrm{g}$ of unlabelled anti-ICAM-1 mAb and $5 \mu \mathrm{g}$ of ${ }^{131} \mathrm{I}$-non-binding $\mathrm{mAb}(\mathrm{P}-23)$ were used. These doses of P-selectin and ICAM-1 mAbs have been shown to saturate all the relevant adhesion receptors expressed after different inflammatory stimuli in rats $[15,16]$. In those experiments in which the relative endothelial surface area was quantified by means of $\mathrm{mAb} 9 \mathrm{~B} 9$ binding, a mixture of $5 \mu \mathrm{g}$ of ${ }^{125} \mathrm{I}-$ 9B9 mAb, $25 \mu \mathrm{g}$ of unlabelled $9 \mathrm{~B} 9$ and $5 \mu \mathrm{g}$ of ${ }^{131} \mathrm{I}-\mathrm{P}-23$, was given through the jugular vein catheter. This dose has previously been useful in assessment of endothelial surface area [16]. Blood samples were obtained through the carotid artery catheter $5 \mathrm{~min}$ after injection of the $\mathrm{mAb}$ mixture. Thereafter, the animals were heparinized ( $1 \mathrm{mg} / \mathrm{kg}$ sodium heparin i.v.) and rapidly exsanguinated. Entire organs were then harvested and weighed.

Calculations. We counted ${ }^{125} \mathrm{I}$ (binding $\mathrm{mAb}$ ) and ${ }^{131} \mathrm{I}$ (nonbinding $\mathrm{mAb}$ ) activities in each organ and in $100 \mu \mathrm{l}$ aliquots of cell-free plasma in a Cobra II gamma-counter (Packard; Meridien, Canberra, Australia), with automatic correction for background activity and spillover. The injected activity in each experiment was calculated by counting a $5 \mu \mathrm{l}$ sample of the mixture containing the radiolabelled mAbs. The accumulated activity of each $\mathrm{mAb}$ in an organ was expressed as ng of binding antibody per $\mathrm{g}$ of tissue. The formula used to calculate either P-selectin, ICAM-1 or ACE expression was as follows: endothelial expression $=\left[\left(\mathrm{cpm}^{125} \mathrm{I}\right.\right.$ organ $\cdot \mathrm{g}^{-1} \cdot \mathrm{cpm}^{125} \mathrm{I}$ inject$\left.\mathrm{ed}^{-1}\right)-\left(\mathrm{cpm}^{131} \mathrm{I}\right.$ organ $\left.\cdot \mathrm{g}^{-1} \cdot \mathrm{cpm}^{131} \mathrm{I}_{\text {injected }}{ }^{-1}\right) \times\left(\mathrm{cpm}^{125} \mathrm{I}\right.$ in plasma $) /\left(\mathrm{cpm}^{131} \mathrm{I}\right.$ in plasma $\left.)\right] \cdot$ ng injected binding $\mathrm{mAb}$.

Experimental protocols. P-selectin and ICAM-1 expression were measured in small bowel and distal colon under baseline conditions in groups of diabetic and non-diabetic rats $(n=6-7$ per group). To determine the effects of I/R on P-selectin expression groups of 5-6 diabetic or non-diabetic animals were 
submitted to $10 \mathrm{~min}$ of ischaemia followed by 10 minutes of reperfusion. Animals submitted to sham ischaemia and studied at the same time periods served as controls. Experiments aimed at assessing ICAM-1 expression were done at $30 \mathrm{~min}$ of reperfusion, following an identical protocol. Additional experiments were designed to evaluate the effect of an NO donor, Spermine NONOate (SP-NO; Caiman Chemical Company, Mich., USA), on P-selectin and ICAM-1 expression at 10 and 30 minutes of reperfusion, respectively. Spermine NONOate was continuously superfused onto the peritoneal cavity throughout the experiment at a concentration of $0.1 \mathrm{mmol} / 1$ that has previously been shown to be effective in preventing $\mathrm{I} / \mathrm{R}$-induced leucocyte recruitment in non-diabetic animals [5, 10].

\section{Northern blot analysis}

Small bowel tissue samples (50-100 mg) from control and diabetic rats were harvested either under basal conditions or after $10 \mathrm{~min}$ of ischaemia and $30 \mathrm{~min}$ of reperfusion. An additional group of diabetic rats received a superfusion of SP-NO $(0.1 \mathrm{mmol} / \mathrm{l})$ onto the peritoneal cavity during $\mathrm{I} / \mathrm{R}$. Total RNA was extracted using Trizol Reagent (Life Technologies, Grand Island, N. Y., USA) and $20 \mu \mathrm{g} /$ sample were electrophoresed on denaturing agarose-formaldehyde gels and transferred overnight to a nylon membrane (ICN Pharmaceuticals, Costa Mesa, Calif., USA) by capillary transfer. Transferred membranes were hybridized with a rat ICAM- 1 cDNA probe radiolabelled with [alpha ${ }^{32} \mathrm{P}$ ]dCTP (Amersham, Buckinghamshire, UK) and exposed to Hyperfilm MP x-ray film (Amersham) at $-800^{\circ} \mathrm{C}$.

\section{Intravital microscopy}

A section of the mesentery was exteriorized and prepared for observation as described previously [16]. A 3CCD camera (DXC-930P, Sony, Tokyo, Japan) mounted on the microscope, projected the image onto a colour monitor and the images were captured on videotape. Single unbranched venules with diameters ranging between 25 and $35 \mu \mathrm{m}$ and a length longer than $100 \mu \mathrm{m}$ were studied. Venular diameter $\left(D_{V}\right)$ was measured on-line using a video caliper (Microcirculation Research Institute, Texas A\&M University, College Station, Tex., USA). The number of adherent, emigrated and rolling leucocytes, as well as their rolling velocity, was measured off-line during playback of videotaped images using criteria described previously [13]. The flux of rolling leucocytes was measured as the number of leucocytes that could be seen rolling within a small $(10 \mu \mathrm{m})$ viewing area of the vessel per min, using the same area throughout the experiment. Centre-line erythrocyte velocity was measured with an optical Doppler velocimeter ( $\mathrm{Mi}$ crocirculation Research Institute). Venular blood flow was calculated from the product of mean erythrocyte velocity $\left(\mathrm{V}_{\text {mean }}=\right.$ Centre-line erythrocyte velocity/1.6) and microvascular cross-sectional area, assuming cylindrical geometry of the vessel. Venular wall shear rate $(\gamma)$ was calculated from the Newtonian definition: $\gamma=8 \cdot\left(\mathrm{V}_{\text {mean }} / \mathrm{D}_{\mathrm{V}}\right)$.

In vivo assessment of free radical generation. To quantify the generation of oxidants by the cells in the area under study, the oxidant-sensitive fluorochrome dihydrorodhamine (DHR)123 (Molecular Probes; Eugene, Ore., USA) was superfused $(10 \mu \mathrm{mol} / \mathrm{l})$ onto the mesentery as described previously [17]. During an initial 30-min stabilization period, the mesenteric preparation was superfused with DHR-free bicarbonate buffer and a background autofluorescence image was recorded. Fluorescence intensity (excitation wavelength, $500 \mathrm{~nm}$; emission wavelength, $536 \mathrm{~nm}$ ) was detected using a 3CCD camera (DXC-930P, Sony). The fluorescence intensity of the venule under study and in the contiguous perivenular interstitium were measured using a computer equipped with the public domain NIH Image digital image processor. An index of free radical generation in the intravascular and interstitial areas was obtained after subtracting background fluorescence from the fluorescence intensity in the region of interest.

Experimental protocols. Once a section of the mesentery was placed on the microscope board a single unbranched venule was selected for study. After a stabilization period of $15 \mathrm{~min}$, images from the mesenteric preparation were recorded on videotape for $5 \mathrm{~min}$. Thereafter ischaemia was induced by pulling the silicone tubing and maintained for $10 \mathrm{~min}$; then the tube was removed, allowing blood to recirculate. In all animals studied a decrease in centre-line erythrocyte velocity of more than $90 \%$ was achieved during the period of ischaemia. All variables were measured again 5 to $10 \mathrm{~min}$ and 30 to $35 \mathrm{~min}$ after reperfusion. In some experiments, SP-NO $(0.1 \mathrm{mmol} / \mathrm{l})$ was added to the superfusate beginning $10 \mathrm{~min}$ before SMA occlusion and lasting throughout the reperfusion period.

\section{Statistical analysis}

All data were analysed using analysis of variance and then a Bonferroni test, and Student's paired or unpaired $t$ test where appropriate. All values are reported as means \pm SEM. Statistical significance was set at $p$ less than 0.05 .

\section{Results}

Effect of an NO donor on $I / R$-induced inflammatory response in diabetic and non-diabetic rats. Compared with controls, diabetic rats showed, under baseline conditions, a significantly higher flux and number of rolling leucocytes (Fig.1). At $10 \mathrm{~min}$ of reperfusion the number and flux of rolling leucocytes increased in both groups of animals reaching similar values, although this increase was only significant in non-diabetic rats and subsequently declined returning to baseline values within $30 \mathrm{~min}$. In control rats, treatment with SP-NO significantly prevented the increment in the number of rolling leucocytes noted during early reperfusion, whereas in diabetic rats the number of rolling leucocytes at $10 \mathrm{~min}$ of reperfusion was not affected by SP-NO and remained significantly higher than values from control non-diabetic rats (Fig. 1).

Leucocyte adhesion and emigration were appreciably increased at $30 \mathrm{~min}$ of reperfusion in control and diabetic rats, although in the latter group these increments were significantly greater. Superfusion of the mesentery with the NO donor completely prevented I/R-induced leucocyte adhesion at 10 and $30 \mathrm{~min}$ of reperfusion, both in control and diabetic rats, whereas emigration was only significantly reduced in the diabetic group (Fig. 2). 


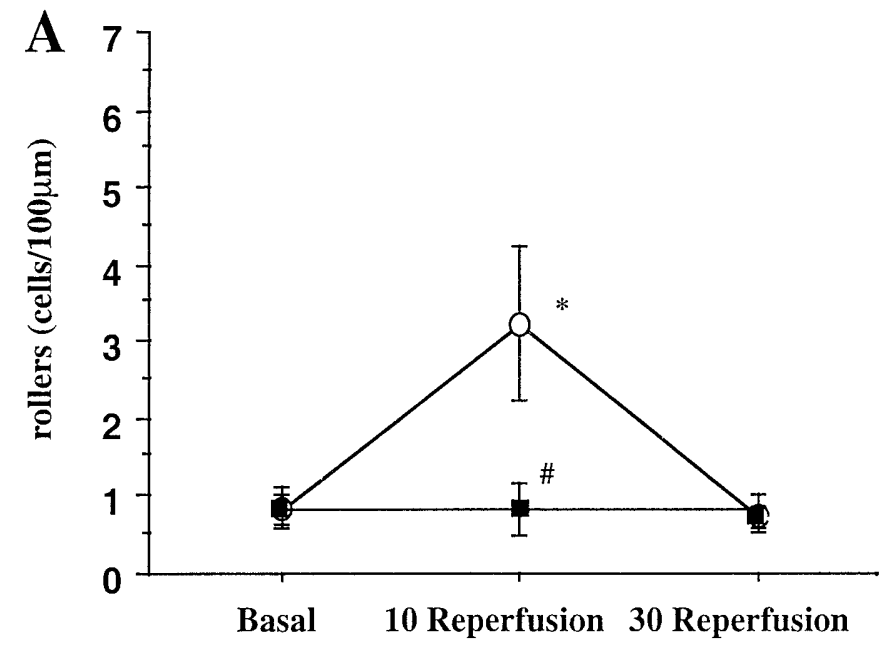

B

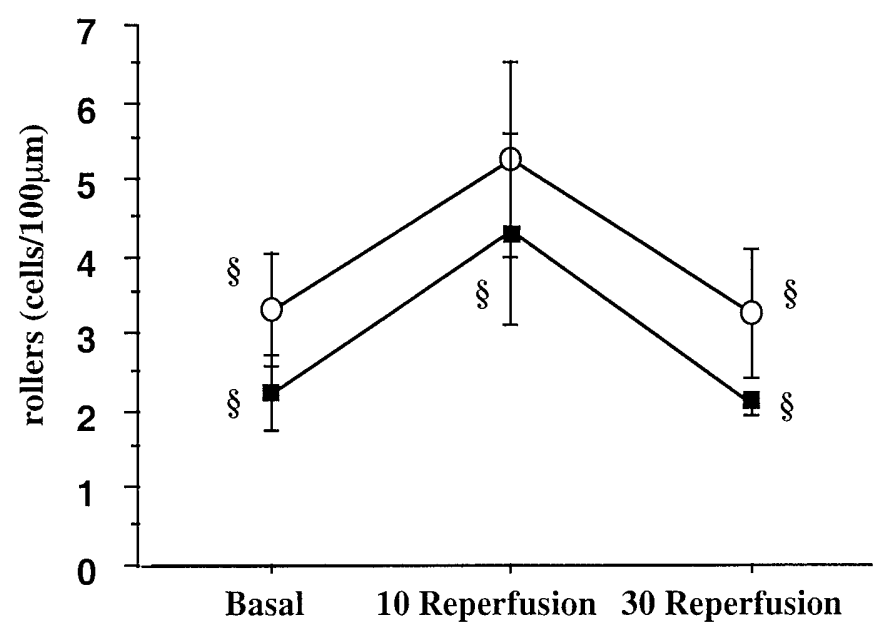

Fig.1A, B. Number of rolling leucocytes (cells/100 $\mu \mathrm{m}$-venule length) in baseline conditions and during reperfusion in control non-diabetic $(\mathbf{A})$ and diabetic rats $(\mathbf{B})$. - $\bigcirc$ - untreated animals. - - Spermine NONOate (SPNO)-treated rats. $* p<0.05$ vs basal. $\# p<0.05$ vs untreated. $\S p<0.05$ vs control non-diabetic

In baseline conditions, diabetic rats had a significantly lower erythrocyte velocity $(3.5 \pm 0.3 \mathrm{~mm} / \mathrm{s}$ vs $2.1 \pm 0.2 \mathrm{~mm} / \mathrm{s} ; p<0.01)$ and shear rate $\left(597 \pm 66 \mathrm{~s}^{-1}\right.$ vs $\left.329 \pm 34 \mathrm{~s}^{-1} ; p<0.005\right)$, relative to control animals. An appreciable fall in shear rate values was observed during early reperfusion and persisted $30 \mathrm{~min}$ later (Fig.3). In control rats, treatment with SP-NO significantly prevented the fall in shear rate noted during early reperfusion, whereas in diabetic animals SPNO superfusion had no effect on the decrease in shear rate (Fig. 3).

Effect of an NO donor on free radical generation during reperfusion. In keeping with previous evidence, mesenteric venules from diabetic rats responded to
$\mathbf{A}$

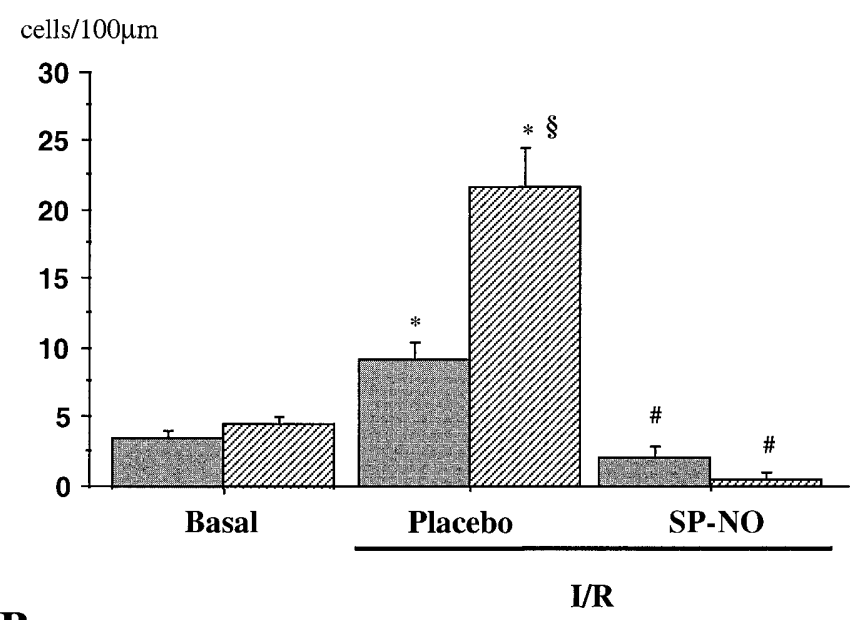

$\mathbf{B}$

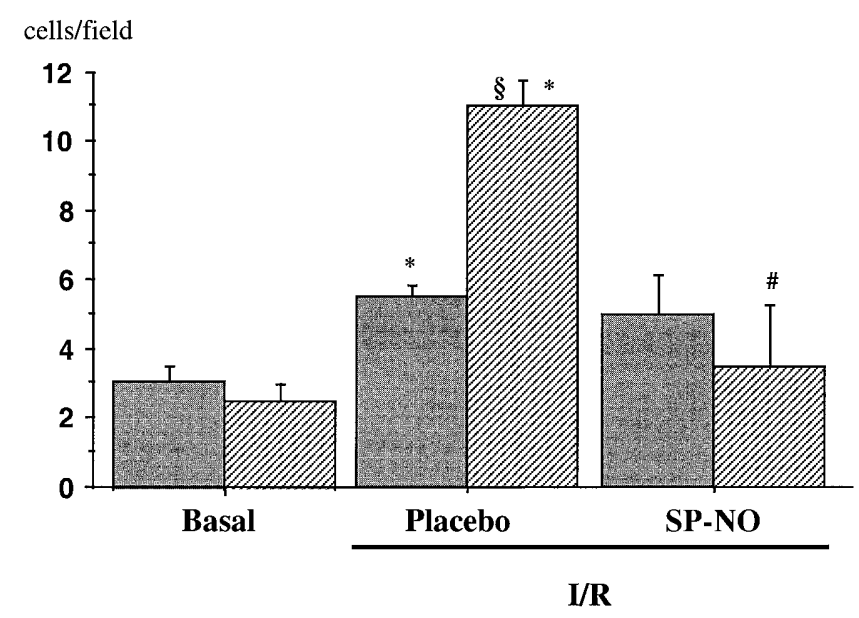

Fig. 2A, B. Leucocyte adhesion (A) and emigration (B) under basal conditions and at $30 \mathrm{~min}$ of reperfusion, in animals receiving placebo or an NO donor. Control animals. W/A Diabetic rats. $* p<0.05$ vs basal. $\# p<0.05$ vs placebo. $\S p<0.05$ vs control non-diabetic

10 min of ischaemia with a significantly higher oxidant production than control non-diabetic rats [18] (Table 1). This overproduction was evident as early as 10 min after the onset of reperfusion and further increased at $30 \mathrm{~min}$. We found that local treatment with NO in diabetic rats significantly reduced DHR oxidation at $30 \mathrm{~min}$ of reperfusion within the venules and in the interstitium to levels similar to those of control animals. In the latter group, DHR oxidation at reperfusion was low and SP-NO did not have any significant effect on oxidant generation (Table 1).

ICAM-1 expression in splachnic organs: effect of $I / R$ and treatment with an NO donor. Under baseline conditions a high ICAM-1 expression was noted in organs from both control and diabetic rats. This constitutive expression was, however, significantly higher in diabetic animals, compared with control rats, both in small bowel and distal colon (Fig.4). As diabetes 

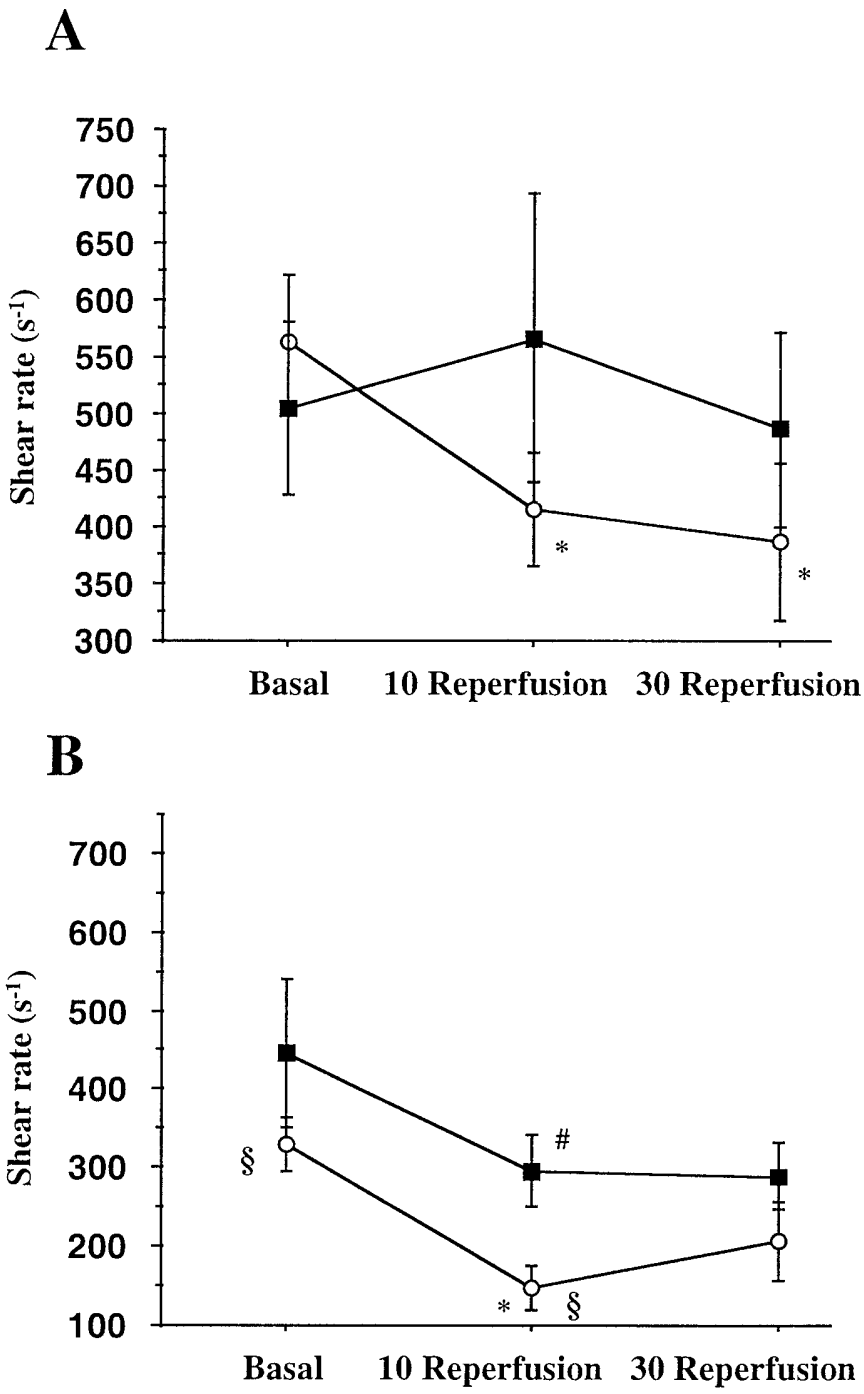

Fig.3A, B. Shear rate $\left(\mathrm{s}^{-1}\right)$ in baseline conditions and during reperfusion in control non-diabetic $(\mathbf{A})$ and diabetic rats $(\mathbf{B})$. -O- Placebo-treated animals. - - Spermine NONOate (SPNO)-treated rats. ${ }^{*} p<0.05$ vs basal. $\# p<0.05$ vs Placebo. $\S p<0.05$ vs control non-diabetic

has been associated with changes in the vascularization of some organs, including the mesentery [16], we estimated endothelial surface area by measuring the accumulation of the anti-ACE mAb 9B9, to correct accumulation of the corresponding $\mathrm{mAb}$ by endothelial surface area when necessary. We found no differences between control and diabetic rats regarding 9B9 binding in small bowel $(26.5 \pm 1.6 \mathrm{ng} / \mathrm{g}$ tissue vs $25.1 \pm 2.9 \mathrm{ng} / \mathrm{g}$ tissue; $p$ :NS), whereas endothelial surface area in the distal colon from diabetic animals was significantly diminished relative to control rats $(26.2 \pm 1.3$ vs $21.2 \pm 1.9 ; p<0.05)$. After correction of anti-ICAM-1 mAb accumulation by endothelial surface area in control and diabetic rats, the same differences were still observed $(8.6 \pm 0.31$ vs $16.6 \pm 1.8$; $p<0.0005)$. Endothelial ICAM-1 expression at $30 \mathrm{~min}$ of reperfusion remained unchanged in non-di-

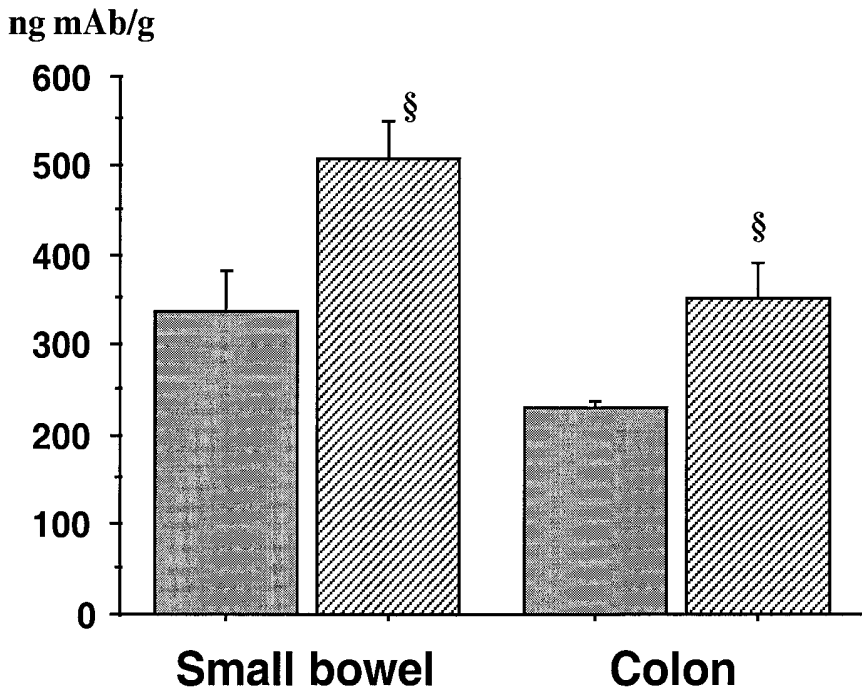

Fig. 4. Constitutive endothelial ICAM-1 expression (ng mAb/ $\mathrm{g}$ of tissue) in small bowel and distal colon from control non-diabetic $(\square)$ and diabetic rats $(\mathbb{Z}) . \S p<0.05$ vs control non-diabetic

Table 1. Generation of reactive oxygen species at $30 \mathrm{~min}$ of reperfusion, as estimated by the increase in fluorescence intensity (arbitrary units) relative to basal values. ${ }^{a} p<0.05$ vs control; ${ }^{\mathrm{b}} p<0.05$ vs placebo

\begin{tabular}{llllll}
\hline & Control & & & Diabetes \\
\cline { 2 - 3 } \cline { 5 - 6 } \cline { 5 - 6 } & Placebo & Spermine & & Placebo & \multicolumn{2}{l}{$\begin{array}{l}\text { Spermine } \\
\text { NO }\end{array}$} & & \multicolumn{2}{c}{ NO } \\
\hline Vessel & $4.0 \pm 1.3$ & $4.0 \pm 1.5$ & & $25.3 \pm 7.6^{\mathrm{a}}$ & $6.5 \pm 2.1^{\mathrm{b}}$ \\
Interstitium & $7.0 \pm 1.0$ & $6.3 \pm 0.6$ & & $20.1 \pm 1.6^{\mathrm{a}}$ & $11.2 \pm 3.0^{\mathrm{b}}$ \\
\hline
\end{tabular}

abetic rats, and similar to those of the sham $\mathrm{I} / \mathrm{R}$ group either in small bowel $(408 \pm 24.8$ vs $422 \pm 27.3$; $p$ :NS) or colon ( $258 \pm 9.5$ vs $279 \pm 8.2$; $p$ :NS.). Note in diabetic rats $\mathrm{I} / \mathrm{R}$ resulted in a significant increment of ICAM-1 expression in the intestine. These increments were abrogated by treatment with SP-NO, showing a protection of NO against rapid ICAM-1 up regulation at reperfusion associated with the diabetic condition (Fig.5).

ICAM-1 mRNA transcription in small bowel samples: effect of $I / R$ and treatment with an NO donor. Basal ICAM-1 mRNA transcription was barely detectable in both control and diabetic rats (Fig. 6; lanes 1-2). Ischaemia for $10 \mathrm{~min}$ followed by $30 \mathrm{~min}$ of reperfusion induced ICAM-1 mRNA transcription in small bowel samples from both groups (lanes 3-8). Northern blot analysis of total RNA extracts showed, however, a much higher increase in ICAM-1 mRNA transcription in the diabetic group (lanes 6-8). Treatment with SP-NO significantly prevented ICAM-1 mRNA transcription during reperfusion in diabetic rats (lanes 9-11). 


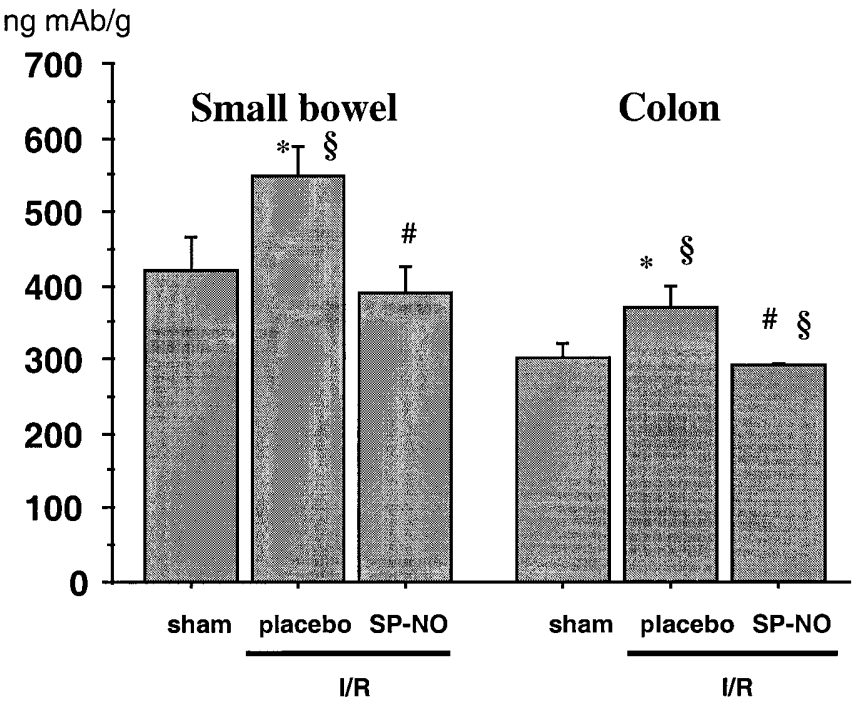

Fig. 5. Endothelial ICAM-1 expression increase at 30 min of reperfusion in small bowel and distal colon from diabetic rats. Effect of spermine NONOate (SP-NO) superfusion. ${ }^{*} p<0.05$ vs sham. $\# p<0.05$ vs placebo. $\S p<0.05$ vs control non-diabetic

$P$-selectin expression in splachnic organs: effect of $I / R$ and treatment with an NO donor. Constitutive expressions of endothelial P-selectin were very low in the small and large bowel. No significant differences were noted between control and diabetic animals regarding P-selectin basal expressions either in small bowel $(2.1 \pm 0.13$ vs $1.5 \pm 0.3, p: \mathrm{NS})$, or distal colon $(0.78 \pm 0.19$ vs $0.52 \pm 0.12, p: \mathrm{NS})$, even after correction by the respective endothelial surface area.

In both control and diabetic rats, P-selectin expression significantly increased within $10 \mathrm{~min}$ of reperfusion in small bowel and distal colon. In non-dia-

Fig. 6. Northern blot analysis of total RNA from small bowel samples. Under baseline conditions ICAM-1 mRNA transcription was not detectable either in control (lane 1) or diabetic (lane 2) rats. I/R induced a mild ICAM-1 mRNA transcription in control rats (lanes 3-5) and a higher increase in diabetic rats (lanes 6-8), that was prevented by spermine NONOate (SP-NO) treatment (lanes 9-11). A small bowel extract from a lipopolysaccharide $(1 \mathrm{mg} / \mathrm{kg})$-treated rat is shown as a positive control (lane 12) betic animals, superfusion of the peritoneum with SP$\mathrm{NO}$ was effective in preventing up regulation of $\mathrm{P}$-selectin during reperfusion in both organs (Fig.7). In contrast, in diabetic rats, SP-NO treatment abrogated $\mathrm{P}$-selectin up regulation at reperfusion in distal colon, whereas it had no effect on small bowel.

\section{Discussion}

A large body of evidence supports the contention that endogenously produced NO could be beneficial after an ischaemic event and that its physiological production is critical in minimizing tissue injury. This view is primarily based on the observation that $N^{\mathrm{G}}$-nitro-L-arginine methyl ester, a potent NO synthesis inhibitor, greatly exacerbates intestinal injury associated with I/R, and L-arginine, the substrate for NO synthesis, reverses its effect [19]. Moreover, NO donors have been widely used to prevent I/R-induced leucocyte recruitment and microvascular dysfunction in non-diabetic animals $[9,10,20]$.

In previous studies we have shown that diabetic rats respond to a short period of mesenteric ischaemia (10 min) with an appreciable inflammatory response which is significantly exacerbated, compared with control rats $[13,16]$. Thus, we first considered whether NO treatment is able to prevent this increased I/R-induced leucocyte recruitment in diabetic rats.

Our results show that treatment with exogenous NO abrogates leucocyte adhesion and emigration during reperfusion of mesenteric postcapillary venules to the same extent in diabetic and control non-diabetic rats. The mechanisms by which NO affords protection in either group of animals appear, however, to be different. Whereas in control rats diminution of leucocyte adhesion and emigration by NO is preceded by a decrease in the number of rolling leucocytes and a restoration of shear rate forces, in diabetic animals NO does not prevent either the increase in the number of rolling leucocytes or the fall in shear rates.

Leucocyte rolling during early stages of reperfusion depends on P-selectin function both in control [5] and in diabetic rats [13]. In keeping with recently published evidence [21], our results show that treat-

\section{$\begin{array}{llllllllllll}1 & 2 & 3 & 4 & 5 & 6 & 7 & 8 & 9 & 10 & 11 & 12\end{array}$}

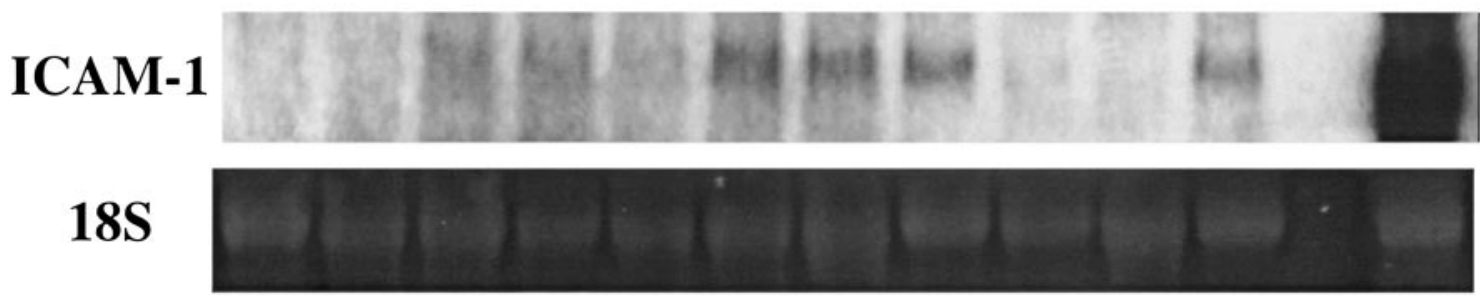


A

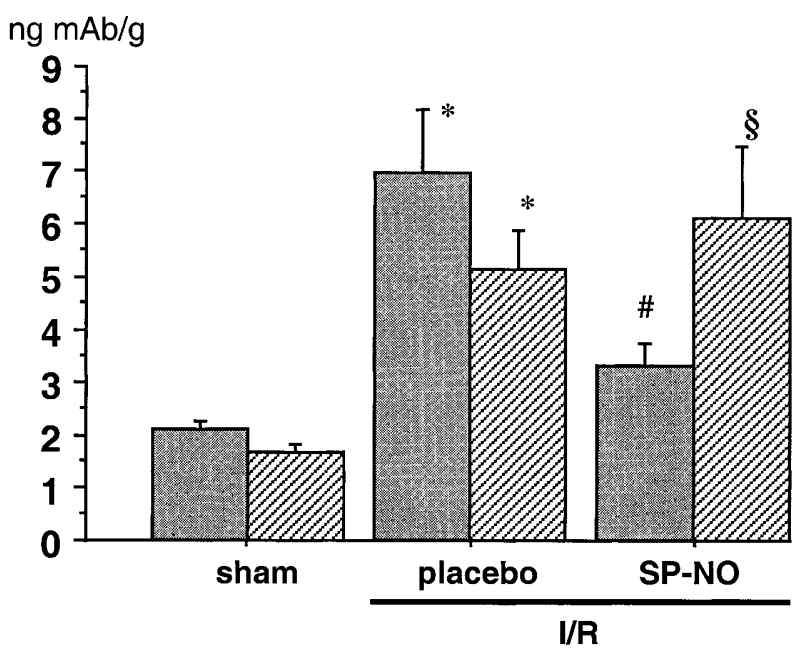

B

ng $\mathrm{mAb} / \mathrm{g}$

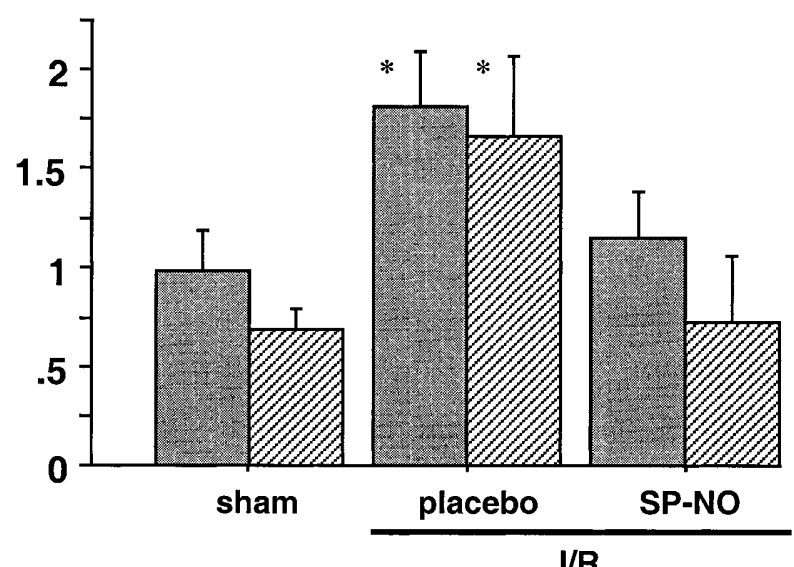

I/R

Fig.7A, B. Endothelial P-selectin expression at $10 \mathrm{~min}$ of reperfusion in small bowel (A) and distal colon (B) from control non-diabetic ( ) and diabetic (ש/A) rats. Effect of spermine NONOate (SP-NO) superfusion. ${ }^{*} p<0.05$ vs sham. \#p $<0.05$ vs placebo. $\S p<0.05$ vs control non-diabetic

ment with an NO donor prevents reperfusion-induced P-selectin up regulation and leucocyte rolling in the non-diabetic condition. In diabetic rats, NO failed, however, to block rolling during reperfusion as well as the increase in P-selectin in some organs such as the small intestine.

Apart from endothelial $\mathrm{P}$-selectin up regulation, leucocyte rolling (and also adhesion) can be influenced by shear stress forces within the vessels. It has been shown that reductions in shear rate induce the recruitment of rolling leucocytes [22] and that up to $60 \%$ of the leucocyte adhesion induced by I/R could be related to the reduced venular shear rates [23]. The increased leucocyte rolling detected under baseline conditions in diabetic rats is largely attributable to the lower shear rates in the venules of these ani- mals and not to differences in P-selectin expression. After reperfusion of ischaemic tissues, we found a decrease in shear rates of $37 \%$ for control rats and $60 \%$ in diabetic rats, compared with their respective basal values. This important fall in shear rate values could conceivably contribute to the increased leucocyte rolling and adhesion observed during reperfusion. In this study, we show that SP-NO in control rats prevented the postischaemic decrease in shear rate. These results support the view that NO donors possibly in part reduce leucocyte adhesion by increasing hydrodynamic forces that strip leucocytes from the vessel wall.

By contrast, in diabetic rats, supplementation with NO did not prevent the fall in shear rate, nor did it significantly reduce leucocyte rolling during reperfusion.

Collectively, these results indicate that, in contrast to the non-diabetic condition, in diabetic animals NO prevents reperfusion-induced leucocyte recruitment in a pathway independent of P-selectin and shear rate.

An alternative mechanism for NO to afford protection is possibly inactivation of superoxide or its derived oxidants. We have previously shown that abrogation of oxidant production during reperfusion in diabetic rats, by means or xanthine oxidase inhibition or superoxide scavenging, significantly reduces leucocyte recruitment during reperfusion [18]. In the current study we observed an appreciable increase in oxidant production at reperfusion in diabetic rats, as measured by DHR oxidation, which was significantly decreased, although not completely abolished, by an NO donor. The remaining oxidative response after treatment with an NO-donor possibly activates the synthesis of vasoconstrictor prostanoids derived from endothelium and accounts for the maintained decrease in shear rate.

Increased concentrations of soluble adhesion molecules, including ICAM-1, have been found in plasma from diabetic patients [24] and have been correlated with glycaemic control [25] and the incidence of diabetic complications [26]. In addition, increased endothelial expression of ICAM-1 has also been reported in target organs from diabetic patients [12] and in experimental models of diabetes [27]. Using the radiolabelled monoclonal antibody technique, which allows a highly precise quantification of adhesion molecule expression, we showed a significantly enhanced ICAM-1 expression in small and large bowel from diabetic animals, compared with normoglycaemic control rats. Hyperglycaemia and its derived oxidative stress have been invoked as a possible mechanism for induced adhesion molecule expression [28]. In vitro studies show that incubation of human umbilical vein endothelial cells with high glucose concentrations [29] or with hyperglycaemic sera from diabetic patients [30] leads to increased ICAM-1 expression. 
Apart from exhibiting higher constitutive ICAM-1 expression, diabetic rats had a rapid and significant up regulation of ICAM-1 as soon as 30 min after the onset of reperfusion. Northern blot analysis indicates that a rapid mRNA transcription in diabetic animals is responsible for this increased expression. The increased production of reactive oxygen metabolites at reperfusion in diabetic animals [18] could account for the enhanced ICAM-1 transcription, as hydrogen peroxide has been shown to rapidly $(30 \mathrm{~min})$ induce ICAM-1 mRNA transcription in cultured endothelial cells [31]. Note, NO supplementation was able to inhibit the increase in ICAM-1 expression, as well as transcription. This observation is in keeping with previous evidence showing that NO modulates adhesion molecule expression (ICAM-1, P-selectin, as well as VCAM-1) in different models of inflammation [21, 32]. The increased up regulation of ICAM-1 in diabetic animals is possibly a critical factor in the enhancement of I/R-induced inflammatory response in diabetes as ICAM-1 is known to have a key role in leucocyte adhesion and emigration, as well as oxidant production, in this animal model of $\mathrm{I} / \mathrm{R}[13,18]$.

In summary, the results from the present study extend our understanding of the mechanisms underlying the increased inflammatory response that accompanies reperfusion events in the diabetic state, namely, an increased oxidant production and ICAM-1 up regulation. The observation that $\mathrm{NO}$ donors reduce the enhanced reperfusion-induced inflammatory lesion in diabetes to the same levels as those in NOtreated non-diabetic animals, suggests that treatment strategies based on NO supplementation could be especially beneficial for diabetic patients.

Acknowledgements. A. Salas and J. Panés were supported by grant SAF 97/0040 from Interministerial Board of Science and Technology (CICYT). D.N. Granger is supported by a grant from the National Heart, Lung and Blood Institute (HL26 441).

\section{References}

1. Ruderman NB, Williamson JR, Brownlee M (1992) Glucose and diabetic vascular disease. FASEB J 6: 2905-2914

2. Kamata K, Miyata N, Kasuya Y (1989) Impairment of endothelium-dependent relaxation and changes in levels of cyclic GMP in aorta from streptozotocin-induced diabetic rats. Br J Pharmacol 97: 614-618

3. Schaeffer G, Wascher TC, Kostner GM, Graier WF (1999) Alterations in platelet $\mathrm{Ca}^{2+}$ signalling in diabetic patients is due to increased formation of superoxide anions and reduced nitric oxide production. Diabetologia 42: 167-176

4. Goor Y, Peer G, Iaina A et al. (1996) Nitric oxide in ischaemic acute renal failure of streptozotocin diabetic rats. Diabetologia 39: 1036-1040

5. Kubes P, Kurose I, Granger DN (1994) NO donors prevent integrin-induced leucocyte adhesion but not P-selectin-dependent rolling in postischaemic venules. Am J Physiol 267:H931-H937
6. Tsao PS, Aoki N, Lefer DJ, Johnson GD, Lefer AM (1990) Time course of endothelial dysfunction and myocardial injury during myocardial ischaemia and reperfusion in the cat. Circulation 82: 1402-1412

7. Wada K, Kamisaki Y, Ohkura T et al. (1998) Direct measurement of nitric oxide release in gastric mucosa during ischaemia-reperfusion in rats. Am $J$ Physiol 274: G465-G471

8. Fukuda H, Sawa Y, Kadoba K, Taniguchi K, Shimazaki Y, Matsuda H (1995) Supplement of nitric oxide attenuates neutrophil-mediated reperfusion injury. Circulation 92: 413-416

9. Payne D, Kubes P (1993) Nitric oxide donors reduce the rise in reperfusion-induced intestinal mucosal permeability. Am J Physiol 265:G189-G195

10. Kurose I, Wolf R, Grisham MB, Granger DN (1994) Modulation of ischaemia/reperfusion-induced microvascular dysfunction by nitric oxide. Circ Res 74: 376-382

11. Wierusz-Wysocka B, Wysocki H, Siekierka H, Wykretowicz A, Szczepanik A, Klimas R (1987) Evidence of polymorphonuclear neutrophils (PMN) activation in patients with insulin dependent diabetes mellitus. J Leukoc Biol 42: 519-523

12. McLeod DS, Lefer DJ, Merges C, Lutty GA (1995) Enhanced expression of intercellular adhesion molecule-1 and $\mathrm{P}$-selectin in the diabetic human retina and choroid. Am J Pathol 147: 642-653

13. Panés J, Kurose I, Rodriguez-Vaca MD et al. (1996) Diabetes exacerbates the inflammatory responses to ischaemiareperfusion. Circulation 93: 161-167

14. Fraker PJ, Speck JC (1978) Protein and cell membrane iodination with a sparingly soluble chloramine. Biochem Biophys Res Commun 80: 849-856

15. Morise Z, Komatsu S, Fuseler JW et al. (1998) ICAM-1 and $P$-selectin expression in a model of NSAID-induced gastropathy. Am J Physiol 274:G246-G252

16. Salas A, Panés J, Elizalde JI et al. (1998) Mechanisms responsible for enhanced inflammatory response to ischaemia-reperfusion in diabetes. Am J Physiol 275: H1773-H1781

17. Panés J, Granger DN (1996) Neutrophils generate oxygen free radicals in mesenteric microcirculation after abdominal irradiation. Gastroenterology 111: 981-989

18. Salas A, Panés J, Elizalde JI, Granger DN, Piqué JM (1999) Reperfusion-induced oxidative stress in diabetes. Cellular and enzymatic sources. J Leukoc Biol 66: 59-66

19. Kubes $P$ (1993) Ischaemia-reperfusion in feline small intestine: a role for nitric oxide. Am J Physiol 264:G143-G149

20. Gauthier TW, Davenpeck KL, Lefer AM (1994) Nitric oxide attenuates leucocyte-endothelial interaction via P-selectin in splanchnic ischaemia-reperfusion. Am J Physiol 267:G562-G568

21. Eppihimer MJ, Russell J, Anderson DC, Epstein CJ, Laroux S, Granger DN (1997) Modulation of P-selectin expression in the postischaemic intestinal microvasculature. Am J Physiol 273:G1326-G1332

22. Bienvenu K, Russell J, Granger DN (1993) Platelet-activating factor promotes shear rate-dependent leucocyte adhesion in postcapillary venules. J Lipid Mediat Cell Signal 8: 95-103

23. Perry MA, Granger DN (1991) Role of CD11/CD18 in shear rate-dependent leucocyte-endothelial cell interactions in cat mesenteric venules. J Clin Invest 87: 1798-1804

24. Lampeter ER, Kishimoto TK, Rothlein R et al. (1992) Elevated levels of circulating adhesion molecules in IDDM patients and in subjects at risk for IDDM. Diabetes 41: 1668-1671 
25. Ceriello A, Falleti E, Bortolotti N et al. (1996) Increased circulating intercellular adhesion molecule-1 levels in type II diabetic patients: the possible role of metabolic control and oxidative stress. Metabolism 45: 498-501

26. Jude EB, Abbott CA, Young MJ, Anderson SG, Douglas JT, Boulton AJ (1998) The potential role of cell adhesion molecules in the pathogenesis of diabetic neuropathy. Diabetologia 41: 330-336

27. Sugimoto H, Shikata K, Hirata K et al. (1997) Increased expression of intercellular adhesion molecule-1 (ICAM-1) in diabetic rat glomeruli: glomerular hyperfiltration is a potential mechanism of ICAM-1 upregulation. Diabetes 46: 2075-2081

28. Ceriello A, Falleti E, Motz E et al. (1998) Hyperglycaemiainduced circulating ICAM-1 increase in diabetes mellitus: the possible role of oxidative stress. Horm Metab Res 30: 146-149
29. Baumgartner Parzer SM, Wagner L, Pettermann M, Gessl A, Waldhausl W (1995) Modulation by high glucose of adhesion molecule expression in cultured endothelial cells. Diabetologia 38: 1367-1370

30. Morigi M, Angioletti S, Imberti B et al. (1998) Leukocyteendothelial interaction is augmented by high glucose concentrations and hyperglycemia in a NF-kB-dependent fashion. J Clin Invest 101: 1905-1915

31. Lo SK, Janakidevi K, Lai L, Malik AB (1993) Hydrogen peroxide-induced increase in endothelial adhesiveness is dependent on ICAM-1 activation. Am J Physiol 264:L406-L412

32. De Caterina R, Libby P, Peng HB et al. (1995) Nitric oxide decreases cytokine-induced endothelial activation. Nitric oxide selectively reduces endothelial expression of adhesion molecules and proinflammatory cytokines. J Clin Invest 96: 60-68 